\title{
A Note on Lapsi Production in Bhaktapur District of Nepal
}

\author{
- Rinita Rajbhandari (Joshi)
}

\begin{abstract}
Lapsi (Choerospondias axillaris: an indigenous fruit tree of Nepal) is grown in temperate climate. The study of socio-economy of Lapsi Fruits in Bhaktapur District of Nepal was conducted in 2016. Bhaktapur district is selected on the basis of coverage area of Lapsi production, processing small scale industries, marketing value and its use by consumers. Forty respondents are selected and interviewed for group discussion and collection of primary and secondary data from different institutions. The coverage of production area of Lapsi fruits is 198.0 hectare and total production is 105.0 metric ton with productivity of 0.9 metric ton per hectare. The harvested Lapsi fruits are sold to local and urban markets. Major processed products of Lapsi fruit are Candy sweet, Candy hot, Titaura, Mada, Pickle, Jam and Lapsi powder. The overall average cost of production of Lapsi fruits is NRs. 2250.0/ropani and gross return NRs.7150.0/ropani with net profit of NRs4900.0/ ropani. Therefore, the benefit cost ratio is 3.1. The wholesale prices of the products Mada, Titaura, Candy sweet, Candy hot, Pickle, Jam and Powder are NRs,. 105.0/

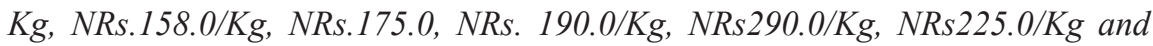
NRs $275.0 / \mathrm{Kg}$ respectively. The study findings suggest that improved varieties of Lapsi fruits should be disseminated to local farmers to increase in production. Government policies should be clear to facilitate Lapsi fruits producers with loans of minimum interest. The quality products of Lapsi candies should be exported as it helps to earn foreign currency and promotes economic development of Nepal.
\end{abstract}

Keywords: Lapsi cultivation, net profit, processing and products export

\section{Introduction}

Lapsi (Choerospondias axillaris) is grown in hills, of $850-1900 \mathrm{~m}$ height. Lapsi trees are distributed from North - East India to South - East China, Japan, Assam, Sikkim, Vietnam, Thailand, and Hongkong. Its tree is used for timber in China and for medical value in Vietnam. Lapsi tree is native to Nepal (Roxburgh, 1832). Lapsi tree is largely known for its delicious fruits in Nepal. The pulp/peel of ripen/raw fruits are use for sweet and sour pickles and candies. The seeds are used for brick kilns. Recent research on preparation of iron impregnated activated

1 Dr. Rajbhandari (Joshi) is an Associate Professor at Institute of Engineering, Pulchowk, Tribhuban University 
carbon from Lapsi seed has shown the potential use for the absorption of arsenic from water (Rajbhandari et al 2011, 2012).

Lapsi has been recognized as one of the potential agro-forestry tree species for income generation to hill farming communities in Nepal (Paudel and Parajuli, 1999, Gautam, 1997 and LARC 1997). Nepal is an agrarian country employing 65 percent of the economically active population. Agriculture is the main source of food, income and employment for majority of the population (CBS, 2011). The share of horticulture in Agriculture Growth Domestic Product (AGDP) is 23 percent. Government of Nepal has emphasized on the production and processing of such high value agro forestry product (APP, 1995). Lapsi fruits cultivation and commercial enterprises can improve the income of farmers and thus, contribute in poverty reduction (FDD, 2014). Government of Nepal, Ministry of Agricultural Development in collaboration with Federation of Nepal Chamber of Commerce (FNCCI) has initiated One Village One Product (OVOP) program of Lapsi fruits to encourage the local community which is processing different Lapsi products in local as well as international market. It helps to generate income for people (FNCCI, 2007).

Bhaktapur district is located in Eastern part of Kathmandu valley. It is almost $21-22 \mathrm{~km}$ far from Kathmandu. Bhaktapur Municipality (Changunarayan) is very popular for Lapsi fruits production. Champak Candy Industry in Bhaktapur was established in 2012. The industry purchases Lapsi fruits for candy processing from local growers. Champak Candy Industry produces many varieties of Lapsi candy. The products of Lapsi candy have a good market in Kathmandu valley as well as out of countries (Champak Candy Industry, 2015).

\section{Data and Methods}

Bhaktapur district is purposively selected for this study based on coverage area of Lapsi growers, production, availability of processing small scale industries, marketing value and its use by consumers. Forty respondents are selected for comparing growers, contractors, middlemen, processors, retailers, wholesalers and consumers. Pre-tested interview schedule, key informant interview, group discussion, primary and secondary data and literatures are collected from government organizations and others institutions. Final collected information is analyzed by the help of SPSS and is also interpreted on paper. 


\subsection{Covered Area and Productivity}

Table 1: Lapsi fruits Covered Area, Production Area and Productivity in Kathmandu 2014/015

\begin{tabular}{|l|l|c|c|c|c|}
\hline S.N & District & $\begin{array}{c}\text { Covered } \\
\text { Area (Ha) }\end{array}$ & $\begin{array}{c}\text { Production } \\
\text { Area (Ha) }\end{array}$ & $\begin{array}{c}\text { Production } \\
\text { (Mt) }\end{array}$ & $\begin{array}{c}\text { Productivity } \\
\text { (Mt /Ha) }\end{array}$ \\
\hline 1 & Bhaktapur & 198.0 & 120.0 & 105.6 & 9.0 \\
\hline 2 & Lalitpur & 15.0 & 15.0 & 150.0 & 10.0 \\
\hline 3 & Kathmandu & 92.0 & 55.0 & 405.0 & 7.4 \\
\hline \multicolumn{2}{|l|}{ Total } & 305.0 & 190.0 & 660.6 & 8.8 \\
\hline
\end{tabular}

Source: Fruit Development Directorate, Kritipur 2014/015

Lapsi fruits can be consumed before and after annual processing. Production of Lapsi fruits is increasing according to the demand of consumers in market. Bhaktapur district is popular cultivator of Lapsi fruit in Nepal. At present, thirty two districts have been producing Lapsi fruits in Nepal. In case of Bhaktapur, Lalitpur and Kathmandu districts, the production areas of Lapsi fruits covered are 198.0, 15.0 and 55.0 hectare, total productions are 105.0, 150.0 and 405.0 metric ton with productivity of $0.9,10.0$ and 7.4 metric ton per hectare respectively. The total Lapsi fruits production area, total production and productivity are 1503.0 hectare, 10488.0 metric ton and 7.4 metric ton per hectare in Nepal (Table 1).

\subsection{Social Activity of Lapsi fruits Production}

Mostly, women are involved in Lapsi production activities like growing, caring and managing orchard but harvesting is done by men. Finally, the harvested Lapsi fruits are assembled, stored, packed, transported and sold to local and urban markets. Besides that, processors are involved in processing raw Lapsi fruits to different products, packaging, labeling, transporting to shops and selling. Finally middle men, wholesalers and retailers are involved in buying of fruits and processed products.

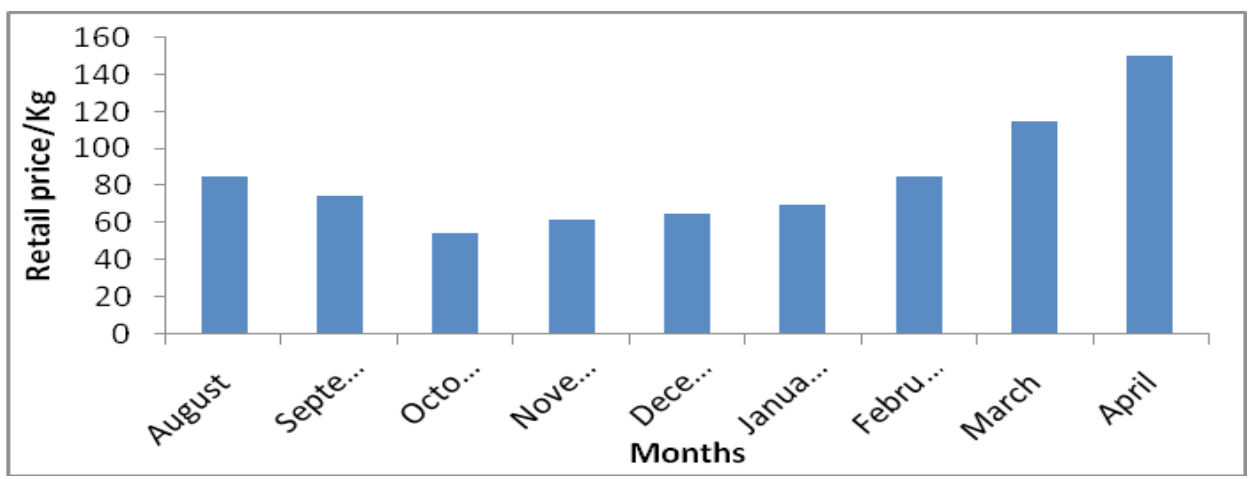

Figure 1. Average Retail price of Lapsi fruits in Bhaktapur district, 2015/016 
Fig 1 shows the retail prices of Lapsi fruits from August to April in the market of Bhaktapur district. Lapsi fruits market depends on its supply and demand of human consumption. The retail price of Lapsi fruits in the months of August, September, October, November, December, January, March and April are NRs.85.0, 75.0, 62.0, 65.0, 70.0, 85.0, 115.0 and 150.0 respectively. The Lapsi fruits prices are high in August with NRs.85.0/Kg and in April up to NRs. 150.0/Kg, because the supply volume of Lapsi fruits is low as compared to October to December.

\section{Analysis of the Use of Lapsi in Different Purposes}

\subsection{Lapsi Liquid (Paun) in Newari dinner}

There are many Newari festivals within a year. Boiled Lapsi fruit along with Samayabaji is worshipped to God and Goddess in Newari festivals. Newari culture serves special Lapsi liquid (paun) as a soup at the end of a heavy dinner because Lapsi liquid helps to digest the meal easily. One kilogram of boiled Lapsi fruit is diluted with approximate two liters of water including taste maker salt, Black salt, red chilly with little fried fenugreek. Lapsi is rich in vitamin C. (Poudel et al 2002).

\subsection{Use of Lapsi fruits pickle}

Lapsi fruit achar is made with combination of radish red/white radish, boiled potato, lapsi powder/ boiled lapsi, green chilly, onion, cucumber, coriander green with little fried fenugreek. Lapsi fruit achar is used for dinner in religious festival and in ceremonies. Lapsi fruit achar is a unique dish well known as an appetizer and helps in food digestion. This Lapsi fruit achar is very popular in Nepalese society.

\subsection{Use of Lapsi fruit processing in different ways}

Lapsi fruit processing is made by mechanical system as well as human hand which is taking place at semi -commercial and commercial market. Some of the major processed products of Lapsi fruit are made to be Candy sweet, Candy hot, Titaura, Mada, Pickle, Jam and Powder while whole lapsi fruit along with seed as well as Pulp can be used for preparing pickle. Pulp is mixed with salt, sugar, chili powder and cardamom. Nowadays pulp is used as dinner menu in Nepalese culture. Preparing Candy, Titaura and Mada, Peel is sundried and it is crushed to prepare powder. The processed product of Lapsi fruit can be used as yearly. The major customers of the processed Lapsi fruit products are women, men, children and tourists of the urban and rural people. There are a few small and medium Lapsi fruit processing industries in Bhaktapur district.

\subsection{Use of Lapsi seed stone}

Lapsi seed stone which contains about $32.8 \%$ fixed carbon is used as a precursor for the preparation of high surface area activated carbon. Activate nanoporous carbon prepared with Lapsi seed powder to $\mathrm{ZnCl}_{2}$ ratio $1: 1$, carbonized at $400^{\circ} \mathrm{C}$ for 4 hour and impregnated with iron showed excellent arsenic adsorption capacity and could decrease arsenic content in water from $800 \mathrm{ppb}$ to below $50 \mathrm{ppb}$. Maximum absorption of $95.9 \%$ was achieved at $\mathrm{pH}>6$. The optimum conditions for adsorbent dose are calculated to $2 \mathrm{~g} / \mathrm{L}$ at pH 6 (Rajbhandari R. 2015). 


\subsection{Comparison of Cost of Production}

Table 2: Average Cost of Production of Lapsi fruits, Cauliflower and Tomato per hectare in Bhaktapur District 2015/016

\begin{tabular}{|l|c|c|c|c|c|c|}
\hline $\begin{array}{l}\text { Fruit and } \\
\text { Vegetable Crop }\end{array}$ & $\begin{array}{c}\text { Cost } \\
\text { (NRs/ } \\
\text { Ropani) }\end{array}$ & $\begin{array}{c}\text { Cost } \\
\text { NRs./ } \\
\text { Kg }\end{array}$ & $\begin{array}{c}\text { Yield } \\
\text { (Kg/ } \\
\text { Ropani) }\end{array}$ & $\begin{array}{c}\text { Gross return } \\
\text { (NRs./ } \\
\text { Ropani) }\end{array}$ & $\begin{array}{c}\text { Net profit } \\
\text { (NRs./ } \\
\text { Ropani }\end{array}$ & $\begin{array}{c}\text { Benefit } \\
\text { Cost/ } \\
\text { Ratio }\end{array}$ \\
\hline Lapsi Fruits & 2250.0 & 17.87 & 400.0 & 7150.0 & 4900.0 & 3.1 \\
\hline $\begin{array}{l}\text { Cauliflower } \\
\text { Local (Local) }\end{array}$ & 20030.0 & 27.13 & 1850.0 & 52200.0 & 32170.0 & 2.6 \\
\hline Tomato (NCL 1) & 26050.0 & 31.88 & 2150.0 & 68570.0 & 42520.0 & 2.9 \\
\hline
\end{tabular}

Source: Lapsi fruits and Vegetable Production in Bhaktapur District, 2015/016

Production cost of Lapsi fruits, Cauliflower and Tomato depends on level of inputs like healthy seedling, manure, fertilizer, human labor, plant protection, chemicals, irrigation and management. The overall average cost of production for Lapsi fruits, Cauliflower and Tomato are NRs. 2250.0, 20030.0 and 26050.0/ropani respectively. While the net return from Lapsi fruits, Cauliflower and Tomato are NRs.4900.0, 32170.0 and 42520.0/ropani. Tomato crop gives more gross return and net profit which were NRs. 68570.0 and 42520.0/Ropani respectively. The benefit cost ratio from Lapsi fruit is 3.1 which is more than 2.6 of Cauliflower and 2.9 of tomato.

Table 3: Processing cost of Lapsi Fruit in Bhaktapur District 2015/016

\begin{tabular}{|l|l|l|}
\hline \multirow{2}{*}{ S.N } & Processing cost of lapsi fruit, NRs./Kg & Bhaktapur District \\
\cline { 2 - 3 } & Particular & 120.0 \\
\hline 1 & Raw ingredients & 18.6 \\
\hline 2 & Packing and labeling & 40.5 \\
\hline 3 & Employment & 12.0 \\
\hline 4 & Marketing & 191.1 \\
\hline 5 & Total & \\
\hline
\end{tabular}

Source: Champak Lapsi Fruit Processing, Bhaktapuir, 2016.

Economic analysis of the cost of lapsi fruit processing of Bhaktapur is shown in Table 3. There are four things which are necessary for processing of lapsi fruits. They are raw ingredients, packing and labeling, human resources and marketing. The cost of raw ingredients, packing and labeling, human resources and marketing per kilogram are NRs.120.0, 18.6, 40.5 and 12.0 respectively. Processing of lapsi fruit products is in high demand in Kathmandu as well as foreign markets. 
Table 4: Average Processing Cost of Lapsi Fruits in Bhaktapur District 2015/016

\begin{tabular}{|l|l|l|}
\hline S.N & Products & Average processing cost NRs./Kg \\
\hline 1 & Mada & 105.0 \\
\hline 2 & Titaura & 158.0 \\
\hline 3 & Candy sweet & 175.0 \\
\hline 4 & Candy hot & 190.0 \\
\hline 5 & Pickle & 290.0 \\
\hline 6 & Jam & 225.0 \\
\hline 7 & Powder & 275.0 \\
\hline Average & & 202.5 \\
\hline
\end{tabular}

Source: Champak Lapsi Fruit Processing, Bhaktapuir, 2016

Average cost of processing products of Lapsi fruits is shown in Table 4. There are seven varieties of processing products of Lapsi fruits. These products are available in Bhaktapur market as well as in Kathmandu market also. The processing products of Lapsi fruits supplier is Champak Lapsi fruits processing. The price of processing Lapsi fruits products are wholesale price and depends upon processing varieties. The wholesale prices of the products Mada, Titaura, Candy sweet, Candy hot, Pickle, Jam and Powder are NRs.105.0/Kg, NRs.158.0/Kg, NRs.175., NRs. 190.0/ $\mathrm{Kg}$, NRs $290.0 / \mathrm{Kg}$, NRs 225.0/Kg and NRs 275.0/Kg respectively. Mada has got the lowest and Pickle has got the highest price among the processed products of lapsi fruits.

\section{Concluding Remarks}

Bhaktapur district is a popular cultivator of Lapsi fruit in Nepal with a production area of 198.0 hectare, production of 105.0 metric ton and productivity of 0.9 ton per hectare. Lapsi fruits are available from August to April. There are some small and medium Lapsi fruit processing industries in Bhaktapur district. The processed products of Lapsi fruit can be used within a year. The net return from Lapsi fruits is NRs.4900.0/ropani and the benefit cost ratio from Lapsi fruit is 3.1. The cost of raw ingredients, packing and labeling, human resources and the end level actors of Lapsi fruits products are value chain. Lapsi seed, a waste agricultural product, can be carbonized to obtain nanoporous activated carbon which can be impregnated with iron (hydro) oxide nano-particles which act as an efficient adsorbent for removing As (III) from water. A good market of Lapsi fruits creates employment opportunities for local people, helps earning foreign currency and develops economy of the country. 
Based on the findings, the study recommends that:

i. Production of Lapsi fruits should be increased in Bhaktapur district. Therefore, research of Lapsi fruits should be continued to improve its varieties through Nepal Agricultural Research Council (NARC).

ii. Training on improved practices of cultivation, harvesting, packing, grading, processing, packaging, labeling and variety should be given.

iii. Collection center and cold storage must be facilitated.

iv. Materials required for harvesting like tarpaulins, nets, ladder are to be provided.

v. Minimum price for Lapsi fruits as well as processed products should be supported.

vi. Candy products of Lapsi fruits should have both quality and quantity.

vii. Hygienic Lapsi candies should be exported as it helps to earn foreign currency and promotes economic development.

viii. Government policies should be clear to facilitate Lapsi fruits candy producers providing loan of minimum interest.

\section{References}

CBS (2010). Statistical pocket book of Nepal, 2010. Government of Nepal, National Planning Commission Secretariat, Central Bureau Of Statistics, Ramshahpath, Thapathali, Kathmandu, Nepal.

Champak Lapsi Candy Product Industry (2015). Candy Product Industry, Bhaktapur, District, Nepal,

FDD (2014). Bagbani Bikash Karyakram, (2014). Fruit Development Directorate, Kirtipur, Kathmandu, Nepal.

FNCCI (2007). Lapsi Fruits Introduction Book, One Village One Product (OVOP) Program Implementation 2007, Federation of Nepal Chamber of Commerce (FNCCI), Agricultural Promotion Center and Nepal Industrial Commercial Association of Nepal, Kalimati, Teku Kathmandu, Nepal.

Gautam K.H. (1997). The sweet and sour tale of Lapsi - Domesticating and commercializing choerosponding axillaris. Agroforestry Today 9 (3): 13 - 16.

LARC (1997). The Strategy for agroforestry research. Lumle agricultural research team LARC strategy paper No. 97/3, Lumle Agricultural Research Center, Kaski, Nepal.

Paudel K.C and Parajuli D.P. (1999). Domestication and Commercialization of Lapsi tree: Scientific World, 1 (1): 116 - 120. Ministry of Science and Technology, Kathmandu, Nepal. 
Paudel K.C., R.Eder, E.Paar and K.Pieber (2002). Chemical composition of Lapsi (Choerospondias axillaries) fruits from Nepal. Mitteilungen Klosterncuburg, 42- 53.

Rajbhandari R (2015). Preparation and Characterization of Activated Carbon from Lapsi(choerospondias axillaries) seed Stone for the Removal of Arsenic (III) from Water, Thesis, Department of Engineering Science and Humanities, IOE,TU.

Rimal S.U. (2016). Value Chain Analysis of Nepali Hog Plum (Choerospondias asillaris) in Bhaktpur and Prabat Districts of Nepal, June 2016, p. 37. 